\title{
Differentiating Among Plant Spectra by Combining pH Dependent Photoluminescence Spectroscopy with Multi-Way Principal Component Analysis (MPCA)
}

\author{
Dean M. Anderson*,a ${ }^{*}$ Timothy L. Danielson ${ }^{\mathrm{b}}$, Safwan M. Obeidat ${ }^{\mathrm{c}}$, Gary D. Rayson ${ }^{\mathrm{d}}$, \\ Rick E. Estell ${ }^{\mathrm{a}}$, Baolong Bai ${ }^{\mathrm{d}}$ and Ed L. Fredrickson ${ }^{\mathrm{a}}$
}

\begin{abstract}
${ }^{a}$ USDA-ARS-Jornada Experimental Range, Las Cruces, NM; ${ }^{b}$ Philip Morris, Richmond, VA; ${ }^{c}$ Department of Basic Sciences, Faculty of Science, Philadelphia University, Amman, Jordan; ${ }^{d}$ Department of Chemistry and Biochemistry, New Mexico State University, Las Cruces, NM
\end{abstract}

\begin{abstract}
Photoluminescence spectroscopic probes offer the potential for differentiation among plant species in real-time. Spectral emission signatures (excitation at $365 \mathrm{~nm}$ ) from three different $\mathrm{pH}$ (2.2, 7.5 and 12.5) phosphate buffered saline (PBS) extracts from two grasses, Sporobolus flexuosus (Thurb. ex Vasey) Rydb., [mesa dropseed], and Pleuraphis mutica Buckley [tobosa], two forbs, Dimorphocarpa wislizenii (Engelm.) Rollins [spectacle pod], and Sphaeralcea incana Torrey [pale globemallow], and leaves and twigs from two shrubs Flourensia cernua DC. [tarbush], and Atriplex canescens (Pursh) Nutt., [fourwing saltbush] were examined. Since $\mathrm{pH}$ has been shown to be pivotal in affecting extraction efficiency of other plant compounds $\mathrm{pH}$ seemed appropriate as an additional dimension within our multi-way principal component analysis (MPCA) to differentiate among six different plant species. In particular, MPCA allowed differentiation between Sporobolus and Pleuraphis that was not possible using only principal component analysis (PCA). This research suggests MPCA may be a more appropriate tool than PCA when attempting to discriminate among plant species.
\end{abstract}

Keywords: Botanical composition, chemometrics, fluorescence, luminescence, phosphate buffered saline (PBS).

\section{INTRODUCTION}

Determining standing crop composition and botanical composition of herbivore diets are the first two steps to optimize free-ranging herbivore nutrition [1]. Knowing if the standing crop contains toxic plants [2-4] or species pivotal to maintaining a desired landscape use [5] are key to managing the plant-animal interface. Using plant spectral signatures to distinguish plant life forms [6] and even genotypes [7] may provide a valuable tool for botanical analysis.

Previous fluorometry research has demonstrated the usefulness of spectroscopic methods for differentiating among pre- $[8-10]$ and post-digested $[6,11]$ species of rangeland vegetation. Though Near Infrared Spectroscopy (NIRS) [12, 13] has been the automated optical method of choice in range animal ecology research, fluorometry [14] appears promising because of its practical differences (Table 1). NIRS [19] as well as fluorometry have the potential to differentiate among plant species. However, within plant life forms, i.e., grasses, forbs and shrubs; it may be challenging to fluorometrically identify individual species without employing appropriate analytical tools. This challenge can be addressed efficiently using mathematical algorithms that take

\footnotetext{
"Address correspondence to this author at the USDA-ARS-Jornada Experimental Range, 2995 Knox, Wooton Hall, Room 240, Las Cruces, NM, 88003, USA; Tel: 575-646-5190; Fax: 575-646-5889;

E-mail: deanders@nmsu.edu
}

advantage of fluorometric data's multidimensional characteristics. Chemometric methods enable the analysis of complex data into sample constituents [20-22]. Distinguishing among species may require data sets with higher ordered dimensionality and use of chemometric procedures involving multi-way principal component analysis (MPCA) developed by Nomikos and MacGregor [23] rather than the simpler mathematical approach involving principal component analysis (PCA) [24-26], applicable to two-dimensional measurements.

These data were collected as part of a previous study to determine the effectiveness of PCA to discriminate among plant species. However, in the study by Danielson et al. [9] PCA was unable to adequately discriminate among visually similar spectral signatures, specifically, differentiation between two grass species was problematic. The objective of this research was to reevaluate a subset of Danielson's data using MPCA to determine if it is superior to PCA in differentiating among visually similar spectral signatures.

\section{MATERIALS AND METHODS}

Plants species potentially consumed by sheep and beef cattle [27-29] were harvested between 6 August and 2 October 1996 on the United States Department of Agriculture's Jornada Experimental Range (USDA-ARS-JER) located in south-central New Mexico, near Las Cruces. The harvested plants represented specimens having similar physiological 
Table 1. Six Practical Considerations when Comparing Near Infrared Reflectance (NIRS) ${ }^{a}$ to Fluorometry ${ }^{b}$

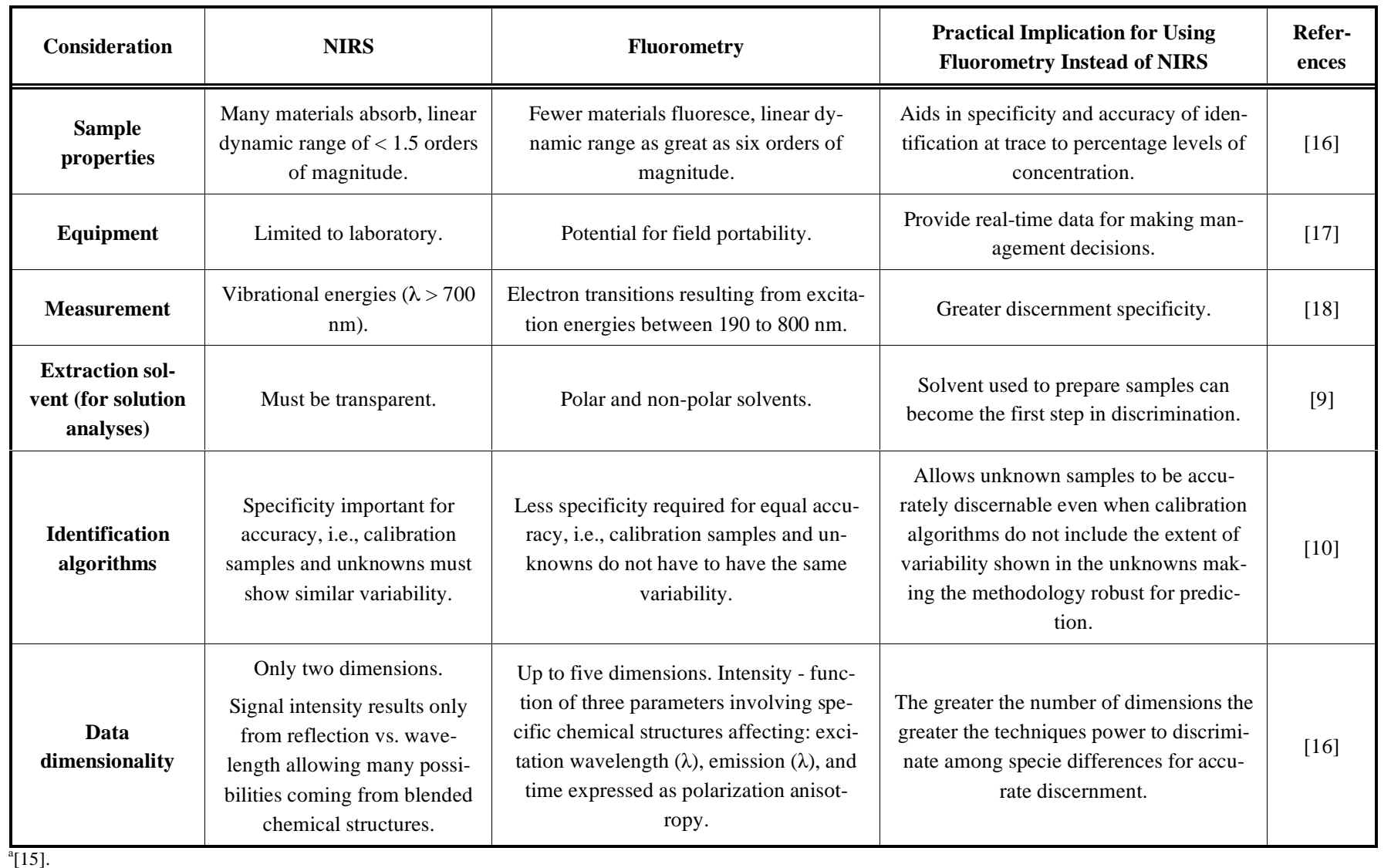

${ }^{\mathrm{b}}[14]$.

maturity (phenology) and were harvested from several different locations on the landscape to provide as much soil and topographic variability as possible. Nine plants from each of six different species were harvested: two grasses, Sporobolus flexuosus (Thurb. ex Vasey) Rydb., [mesa dropseed], and Pleuraphis mutica Buckley [tobosa]; two forbs, Dimorphocarpa wislizenii (Engelm.) Rollins [spectacle pod], and Sphaeralcea incana Torrey [pale globemallow]; and two shrubs consisting of leaf and stem material, Flourensia cernua DC. [tarbush] leaves and Atriplex canescens (Pursh) Nutt., [fourwing saltbush] leaves and current years stem growth (twigs) were obtained. The plant nomenclature follows that of Allred [30].

The 36 herbaceous plants, nine from each of four species, were clipped at ground-level while leaves from nine tarbush plants and leaves and twigs from nine fourwing saltbush plants were stripped from branches giving a total of 54 unique plant samples to be analyzed. Detailed sample collection and preparation protocol can be found in Danielson et al. [9]. Harvested plant materials were oven-dried to a constant mass at $60^{\circ} \mathrm{C}$ before the contents of each of the 54 bags were ground to pass a $1-\mathrm{mm}$ micro-Wiley mill screen. The ground plant material was collected in labeled plastic vials and stored at room temperature. Immediately prior to fluorometric analysis, the vial contents were re-dried at $60^{\circ}$ $\mathrm{C}$ and triplicate $0.15 \mathrm{~g}$ samples of the dried material from each of the 54 vials were weighed into labeled glass culture tubes, sealed with Parafilm ${ }^{\circledR}$, and stored at room temperature. A $10 \mathrm{~mL}$ volume of phosphate buffered saline (PBS), con- taining sodium azide (to inhibit microbial growth), at one of three $\mathrm{pH}$ values $(2.2,7.5$, or 12.5$)$ was added to each of the 162 tubes. These $\mathrm{pH}$ values were chosen to ensure that the highest buffering capacity of the solvent would be maintained following the extraction procedure thus preventing changing of the extract's pH. Details of how the PBS and three $\mathrm{pH}$ solutions were made have previously been published [9]. The filled tubes were shaken for one hour at 900 RPM followed by filtration through Whatman No. 4 paper into clean, labeled tubes, sealed with Parafilm ${ }^{\circledR}$, and stored at $3^{\circ} \mathrm{C}$ until analysis.

Besides being environmentally safe, PBS was used to minimize chlorophyll extraction [9] and to minimize pre-and post- spectral filtering effects. Danielson et al. [9] reported the need to dilute the resulting plant extract solutions $(\mathrm{a} \mathrm{pH}$ $2.2,7.5$, and 12.5 ) by factors of $12.50 \%, 6.25 \%$, and $3.13 \%$, eg. $1 \mathrm{ml}$ of extract was diluted to a total of 8,16 , and $32 \mathrm{ml}$ of the appropriate $\mathrm{pH}$ buffered solutions, respectively. $\mathrm{Re}$ search has revealed that extraction solvents having different $\mathrm{pH}$ values can be useful in extracting various compounds including pectin [31] and glutaric, malic and maleic acids found in plants [32]. Therefore, extracting solution $\mathrm{pH}$ was included as a variable in the present study.

Excitation radiation of $365 \mathrm{~nm}$ was selected from a 500 W Xe/Hg-arc lamp using a $0.25 \mathrm{~m}$ monochromator (Melles Griot, Model HR-20, [9]). The emitted radiation was collected and transferred using F-matching transfer optics [33] to the entrance slit of a $1.0 \mathrm{~m}$ focal length monochromator 
equipped with a $1200 \mathrm{~mm}$ holographic grating with a $1.7 \mathrm{~nm}$ bandpass (2.0 mm entrance and exit slit widths). Use of the holographic grating resulted in the Wood's grating anomaly [34-36] being observed and it was left uncorrected. It manifested itself as an apparent local minimum in all spectra at $\sim 515 \mathrm{~nm}$. This study was not designed to determine the molecular species responsible for the various fluorometric signatures; therefore, the uncorrected spectra reported using this system are not directly transferable to other spectroscopic configurations. Fluorometric instrumentation details have been previously described by Danielson et al. [9].

Data acquisition was accomplished using in-house software developed using LabView ${ }^{\circledR} 5.0$ (National Instruments). Data analysis utilized algorithms found in the PLS-Toolbox (Eigenvector Research, Wenatchee, WA) operated within MATLAB (Mathworks, Lowell, MA).

\subsection{Multi-Way Principal Component Analysis (MPCA)}

The fluorescence emission data consisted of broad and superimposed spectral features from yet to be identified fluorophores within the $375-620 \mathrm{~nm}$ region of the spectrum. This technique neither enables a comprehensive molecular component level understanding of the spectral response curve (fingerprint) nor relies on the identification of the specific molecular species. However, this spectral approach has been found useful in differentiating among plants.

Earlier use of PCA by Danielson et al. [9] involved decomposition of the two-dimensional data matrix (i.e., emission intensities at each of 247 wavelengths for each of the six plant species) into a collection of principal components and an error matrix. PCA can only deal with twodimensional data matrices. Conversely, MPCA enables analysis of three dimension data matrices.

Though statistically and mathematically similar to PCA, MPCA (also called unfolded PCA or U-PCA) involves the generation of a representation of the eigenvectors for the covariance or correlation matrix of the original measured variable data matrix [37]. Simply stated, MPCA enables the discernment of principal components within an entire data set that account for the variance present in those data and an effective reduction of the effective variables describing each sample. It should be noted that for both PCA and MPCA, the emission response curve or surface, respectively, is used in the analysis of the collected measurements thereby eliminating the need for any subjective selection of specific variables (e.g., wavelength or wavelength and $\mathrm{pH}$ ). For a more detailed discussion of the MPCA procedure, see Obeidat et al. [10] and cited references therein. Although there are other data analysis tools that can be applied to data sets with higher dimensionality (e.g., measured intensities as a function of more than one variable), previous use of PCA suggested that an expanded form of the same approach would enable segregation of plants using emission intensities as a function of both wavelength and extracting solution $\mathrm{pH}$.

Using MPCA makes it possible to differentiate, identify, and classify plant material without any a priori information [37-39]. In our data, $\mathrm{pH}$ served as the third dimension because of its usefulness in extracting different plant compounds. The extracts from the six plant species used in this research were run independently at three $\mathrm{pHs}(2.2,7.5$, and
12.5). This allowed us to build a two way data matrix at each $\mathrm{pH}$ with dimensions of $247 \times 6$ for total dimensionality of $247 \times 6 \times 3$.

\section{RESULTS AND DISCUSSION}

\subsection{Observed Fluorescence}

Spectra were normalized to their respective intensity maxima to enhance both the observed differences and similarities among the six plant species. The $420 \mathrm{~nm}$ peak observed at all three pHs (Fig. 1A, B and $\mathbf{C}$ ) can be attributed to a Raman scattering band arising from the water based solvent [9]. Efforts to eliminate this artifact through background correction yielded either sample-dependent under or over correction. This suggests the presence of a sample-dependent attenuation from pre- or post-filter effects by absorbing concomitant molecular species. Correction for this feature was not undertaken eliminating the ability to compare these data with similar fluorometric studies.

\subsection{Effect of Solvent pH on Fluorescence Spectra}

The PBS extracts at the acidic pH (2.2) appeared to produce visually similar fluorescence spectra among the six plant species (Fig. 1A). In contrast, the solvents at a neutral $\mathrm{pH}$ of 7.5; (Fig. 1B) and an alkaline $\mathrm{pH}$ of 12.5; (Fig. 1C) produced spectral signatures with greater visual variation among the six plant species. Overall, fluorescence was observed in two regions of the visible spectrum. One region exhibited a maximum between $440-470 \mathrm{~nm}$ (blue) with a shift to longer wavelengths (red shift) as $\mathrm{pH}$ was increased from 2.2 to 12.2 (Table 2 ). The other visually distinguishable region occurred at $\sim 523 \mathrm{~nm}$ (green) but it did not exhibit a red shift with $\mathrm{pH}$ (Table 2). This suggests that blue-emitting fluorophore(s) exhibited greater $\mathrm{pH}$ dependence among the six different plant species than those emitting in the green.

The two grasses, mesa dropseed and tobosa, showed very similar fluorescence responses at $\mathrm{pH} 2.2$ and $\mathrm{pH} 7.5$ (Figs. $\mathbf{2 A}$ and 2B) making them visually indistinguishable between 375 and $\sim 414 \mathrm{~nm}$. This similarity thwarted PCA from being able to discern between these two plants [9].

Spectra obtained from spectacle pod extracts at $\mathrm{pH} 7.5$ demonstrated a significant increase in one or more compounds that fluoresced in the green region $(515-525 \mathrm{~nm})$ of the spectrum compared to those components responsible for blue (375-498 nm) emission. Furthermore, spectacle pod at pH 7.5 did not exhibit the same red shift as did tarbush. Tarbush demonstrated an interesting characteristic in having the largest relative green wavelength $(523 \mathrm{~nm})$ emission among all the six plant species evaluated. The red shift of emission wavelength with increasing extraction $\mathrm{pH}$ can be seen in Table 2. These observations can be explained by extraction of a longer wavelength emitting fluorophore resulting in the measured red shift. In similar studies, Billa et al. [21] in wheat straw, sorghum fiber and sweet sorghum stalks demonstrated $\mathrm{pH}$ dependent fluorescence spectra could be used to distinguish types of pulps used in the manufacture of various papers. The alkaline treatment of grass and legumes with $\mathrm{NaOH}$ has been shown to release the phenolic compounds, ferulic acid and $p$-coumaric acid, from cell walls and these phenolics have therefore been proposed to be major contributors to plant fluorescence in the blue-green region of the 
Table 2. Maximum Blue (424.0-491.2 nm) ${ }^{\mathrm{a}}$ and Green $(491.3-575.0 \mathrm{~nm})^{\mathrm{a}}$ Emission Wavelengths $(\lambda)$ and Blue to Green Emission Wavelength Ratios along with an Intensity Ratio of the Maximum Blue Emission Intensity to the Maximum Green Intensity for Six Ground Arid Rangeland Forage Species Extracted with Buffered Saline at Three pH Values. The Grasses, Forbs and Shrubs were Exposed to a $365 \mathrm{~nm}$ Excitation Wavelength from a $500 \mathrm{~W}$ Xe/Hg-Arc Lamp

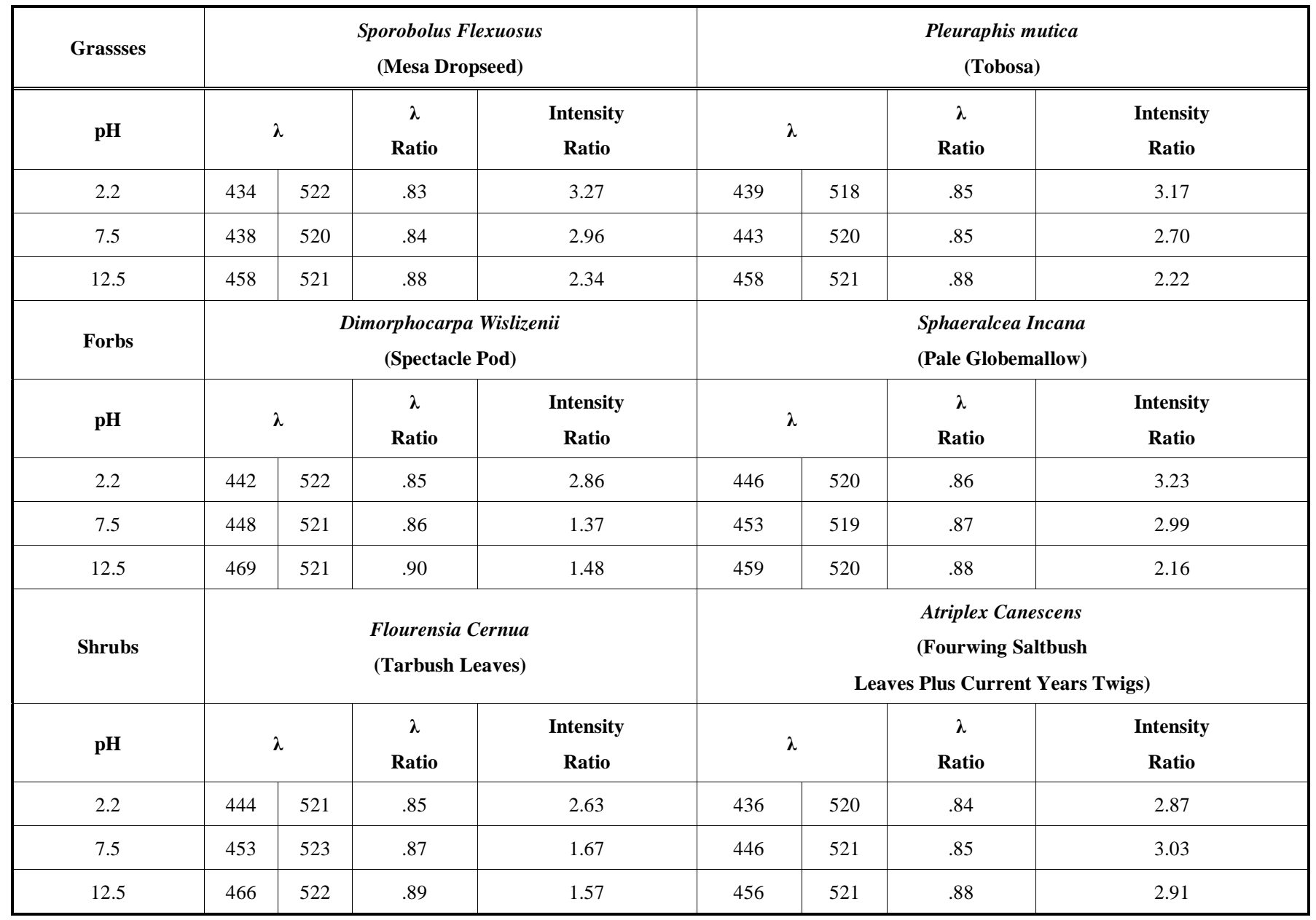

${ }^{\mathrm{a}}[40]$.

visible spectrum [41]. Furthermore, these researchers concluded that the relative concentrations of these molecules vary among various grass species, although this conclusion suggests genetic differences based on plant species. Other explanations of these variations await investigation, (e.g., differences related to changes in plant physiological state or a combination of other biotic or abiotic factors acting either independently or synergistically). Although plant chemical composition can vary due to many factors [42], it is unknown how these chemical changes affect fluorometry. Visual evaluation of mean fluorescence spectra from the six different plant species at each pH (Fig. 1A through C) indicated both similarities and differences.

The forbs (spectacle pod and pale globemallow) and shrubs (tarbush and fourwing saltbush) appear to exhibit higher extraction efficiency for green-emitting fluorophores regardless of $\mathrm{pH}$ (i.e., the ability to transfer one or more chemical compounds from the plant sample into the PBS solution). Additionally, shifts in wavelengths of maximum emission between each of the forbs and two shrubs towards the red (i.e., longer wavelengths) were observed. At neutral and high $\mathrm{pH}$, the fluorescence responses in both forbs and shrubs appear to be visually distinguishable. Two distinctive peaks were observed from the data; one centered at $\sim 450 \mathrm{~nm}$, the other at $\sim 525 \mathrm{~nm}$.

A similar study reported by Johnson et al. [43] indicated peak similarities and differences for seven different types of plants consisting of five species each of grasses/sedges, conifers, herbaceous dicotyledons, succulents, palms, woody deciduous dicotyledons, and woody evergreen dicotyledons. They observed for all 35 species a violet to blue emission peak with a maximum between $405-475 \mathrm{~nm}$, while in about one third of their species they observed a predominant green emission peak between 510-550 nm. Although not seen in the present study, one species of plant (Aloe barbadensis, a succulent) was reported to exhibit an emission maximum at $568 \mathrm{~nm}$ [43]. It should be noted that samples in the Johnson study were prepared from the adaxial and abaxial surfaces of plant foliage while our samples were aqueous plant extracts from ground whole plants or plant parts.

There have been many suggestions as to what fluorophores are responsible for the observed fluorescence spectra (Table 3). The UV-induced fluorescence of specific organic compounds known to be endogenous to plant leaves has also 

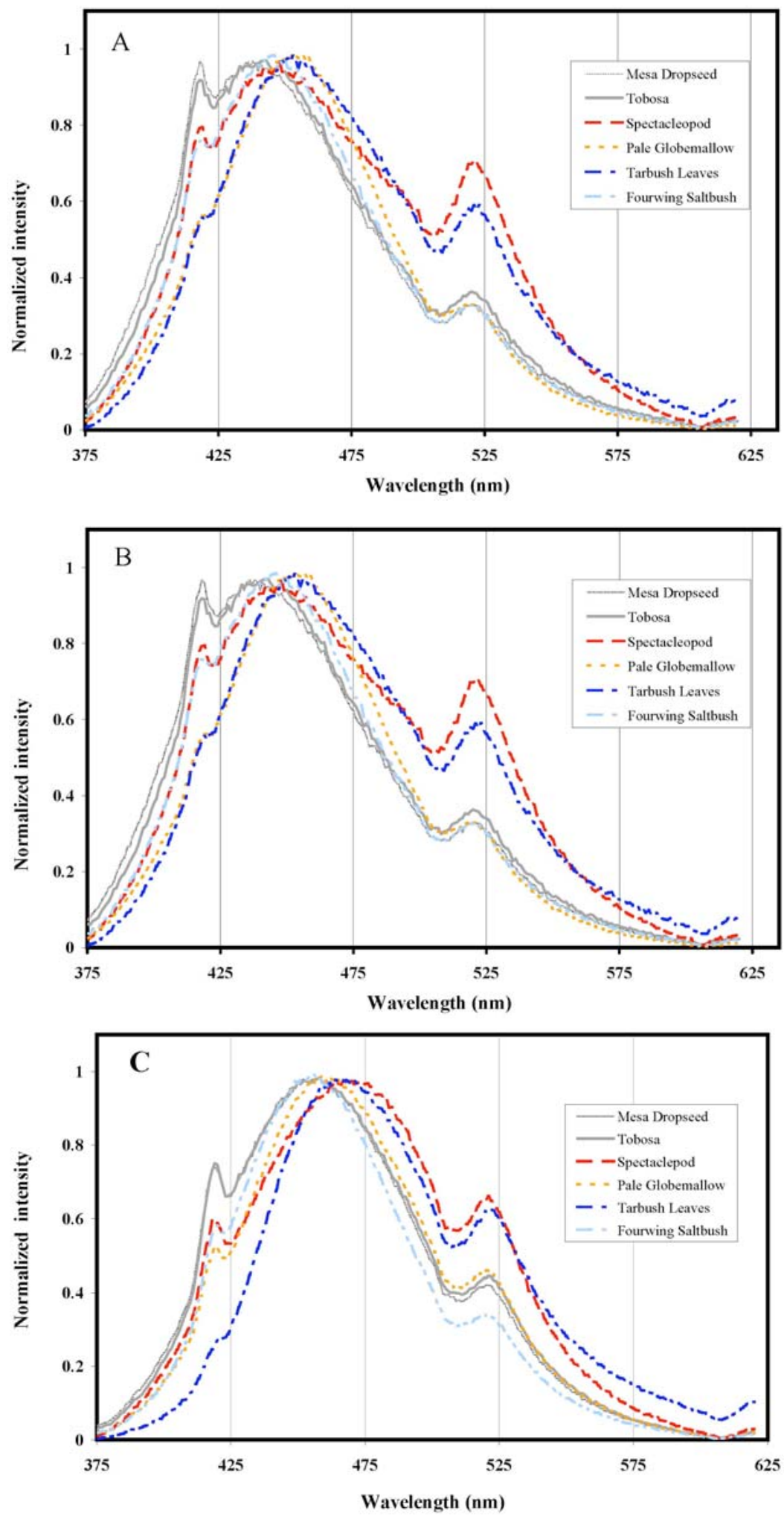

Fig. (1). Mean $(n=9)$ normalized emission spectra for phosphate buffer saline (PBS) extracts of two grasses, two forbs and two shrubs (leaves and current year's twigs only for shrubs) at three $\mathrm{pHs}(\mathrm{A}=2.2 ; \mathrm{B}=7.5$ and $\mathrm{C}=12.5)$.

been reported. It should be noted with respect to the present study that coumarins tend to fluoresce more intensely in alkaline solutions while not at all in acidic solutions. Hence, these types of compounds may have contributed to the redshift observed in the present study. 

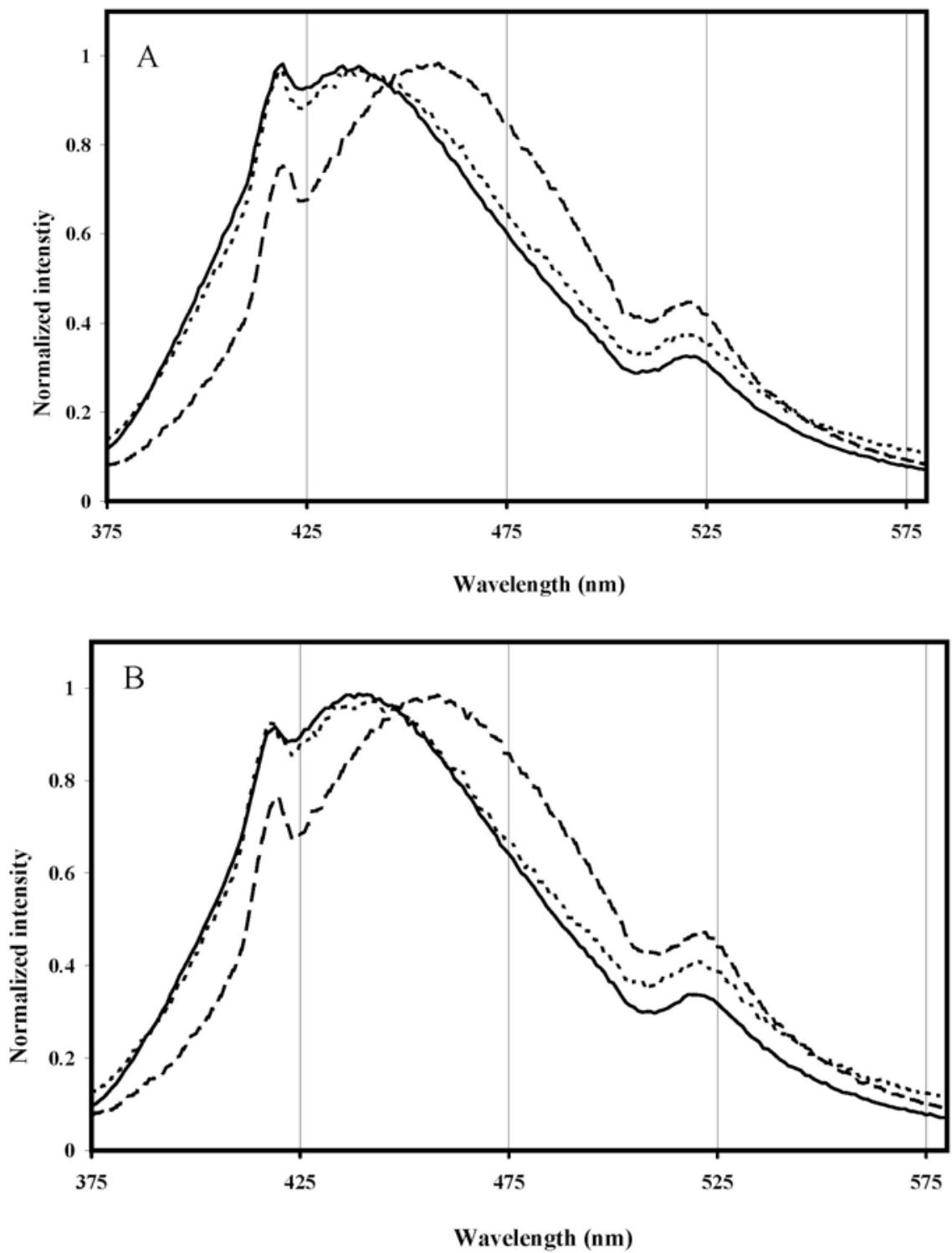

Fig. (2). Mean ( $\mathrm{n}=9)$ normalized emission spectra for phosphate buffered saline (PBS) extracts of A) Sporobolus flexuosus [Thurb.] Rydb., mesa dropseed, B) Pleuraphis mutica Buckley, tobosa at pH values of $2.2(--), 7.5(\bullet \bullet)$, and $12.5(---)$.

Table 3. Plant Molecules Known to Fluoresce

\begin{tabular}{|l|c|c|}
\hline \multicolumn{1}{|c|}{ Molecules } & Emission Wavelength $(\lambda)$ & \multicolumn{1}{|c|}{ References } \\
\hline \hline Chlorophyll a & 666 \\
\hline Chlorophyll b & 430 (bound to proteins) & {$[44]$} \\
\hline NAD(P)H & \& 460 (free form) & 525 \\
\hline FAD, FMN, Riboflavin & 440 & {$[45-47]$} \\
\hline $\begin{array}{l}\text { Caffeic acid, Ferulic acid, Chlorogenic acid, Sinapic acid, (+) Catechin and Phyllo- } \\
\text { quinone (reduced form) Aesculetin, Scopoletin }\end{array}$ & {$[47]$} \\
\hline t-stilbene, Rhaponticin & 380-390 \\
\hline Berberine, Quercetin & $520-530$ & {$[47]$} \\
\hline
\end{tabular}




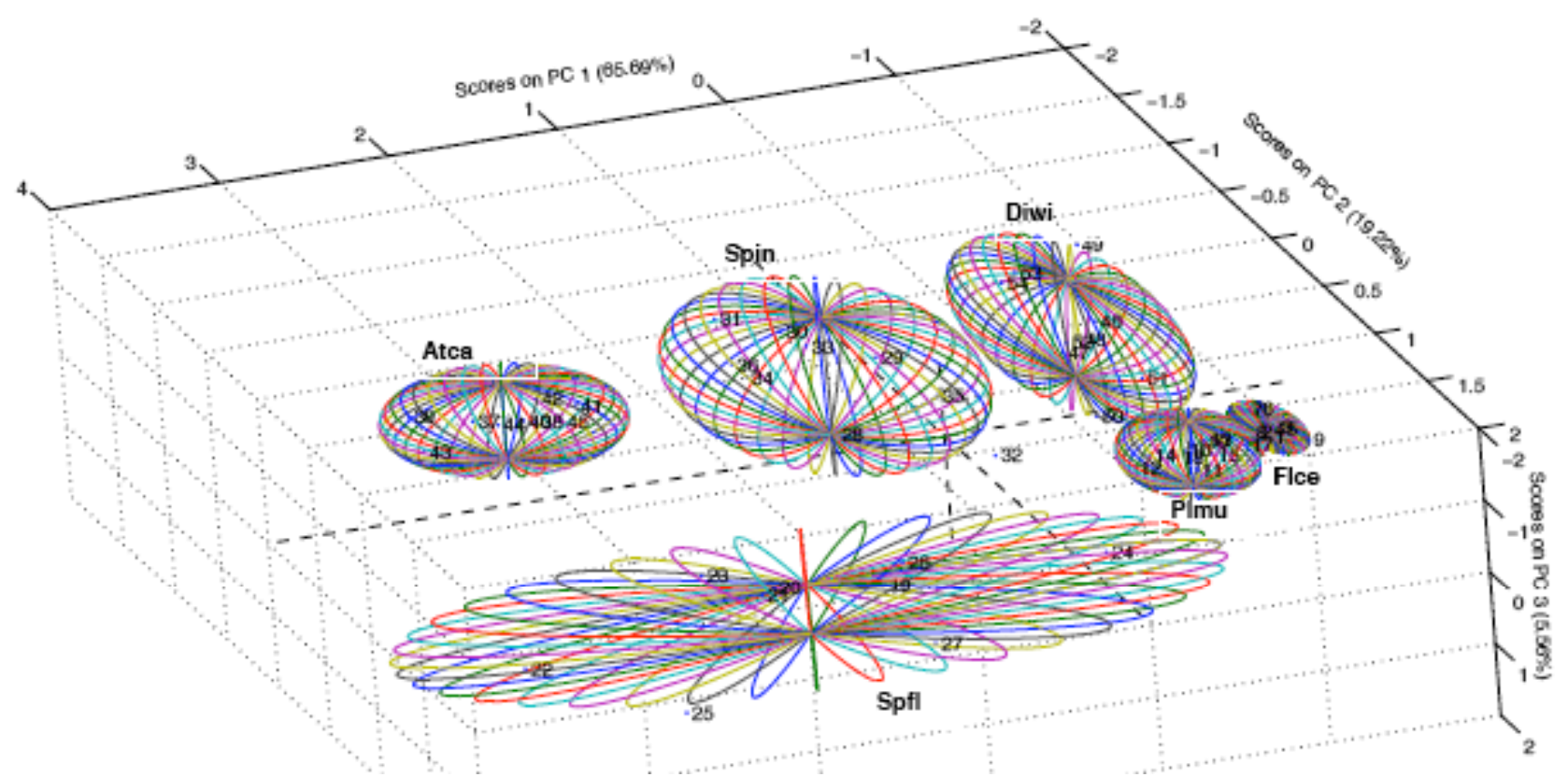

Fig. (3). Plot of PC scores showing six species (Sporobolus flexuosus (Spfl), Pleuraphis mutica (Plmu), Dimorphocarpa wislizenii (Diwi), Sphaeralcea incana (Spin), Flourensia cernua (Flce) and Atriplex canescens (Atca)) each with nine plants per species resulting from the application of a multi-way principal component analysis (MPCA) data analysis of the pH-dependent emission spectra from each phosphate buffered saline solution extract of plant species samples. The three dimensions of the data set were signal intensity as a function of emission wavelength and extracting solution $\mathrm{pH}$. The numbers correspond to samples from individual plants. Ellipsoids depict $95 \%$ confidence volumes about the centroid projection of each plant species (see Table 4).

Table 4. Confidence Surface Values (95\%) for Each Species, see Fig. (3)

\begin{tabular}{|c|c|c|c|c|c|c|c|c|c|}
\hline \multirow{3}{*}{ Plant Species } & \multicolumn{3}{|c|}{ Centroid of Each Elipsoid } & \multicolumn{6}{|c|}{ 95\% Confidence Ellipsoidal Surfaces } \\
\hline & \multirow{2}{*}{ PC1 } & \multirow{2}{*}{ PC2 } & \multirow{2}{*}{ PC3 } & \multicolumn{2}{|c|}{ Score 1} & \multicolumn{2}{|c|}{ Score 2} & \multicolumn{2}{|c|}{ Score 3} \\
\hline & & & & Upper & Lower & Upper & Lower & Upper & Lower \\
\hline Sporobolus flexuosus (Mesa dropseed) & -1.58 & 0.56 & -0.27 & -1.40 & -1.76 & 0.82 & 0.30 & -0.15 & -0.39 \\
\hline Pleuraphis mutica (Tobosa) & -1.17 & 0.45 & 0.08 & -0.78 & -1.56 & 0.78 & 0.13 & 0.53 & -0.36 \\
\hline Sphaeralcea incana (Pale globemallow) & 0.03 & -1.13 & 0.65 & 0.88 & -0.82 & -0.32 & -1.95 & 1.47 & -0.17 \\
\hline Flourensia cernua (Tarbush leaves) & 2.31 & -0.45 & -0.48 & 3.01 & 1.61 & -0.05 & -0.86 & 0.05 & -1.01 \\
\hline $\begin{array}{l}\text { Atriplex canescens (Fourwing saltbush leaves plus } \\
\text { current years twigs) }\end{array}$ & -1.13 & -0.60 & -0.28 & -0.60 & -1.65 & 0.24 & -1.45 & 0.39 & -0.96 \\
\hline
\end{tabular}

Our data suggest that using extraction solutions differing in $\mathrm{pH}$ may be a useful first step when attempting to distinguish among various plant species if MPCA procedures are used. Danielson et al. [9] determined that the scores of the first three PCs from a PCA model of emission spectra of solutions at each $\mathrm{pH}$ value enabled adequate separation among all plant species except for the two grasses while accounting for more than $95 \%$ of the total variation within the extract spectral signature. However, separation of the two grasses (tobosa and mesa dropseed) remained unrealized.

Three two-way data matrices corresponding to each extract solution $\mathrm{pH}$ were concatenated into a single data matrix with three dimensions of $247 \times 3 \times 6$. Application of MPCA to this matrix yielded a separation enhancement for all six plant extracts. This approach increased the dimensionality of the data set by incorporating data from all three $\mathrm{pH}$ extracts simultaneously enhancing separation among the six plant species (Fig. 3). This enabled the successful separation of all six species using scores from the first three PCs in an MPCA model in which $95 \%$ of the total variation was accounted for. This three dimensional data set was composed of the twoway MPCA models using the first versus the second and the first versus the third PCs. Fig. (3) shows that by increasing the dimensionality of the data using three $\mathrm{pH}$ values the technique's ability to separate fluorometric signatures improved. Spectra from each of the 54 plants show the variability around each of the six specie groupings (Fig. 3) is less 
than that among the six species (Table 4). Ellipsoidal surfaces in Fig. (3) indicate volumes defined by $95 \%$ confidence intervals relative to the centroid location of score projections of combined spectra from plants of a specific species. Separation of ellipsoids then illustrates significant (i.e., $>95 \%$ confidence) differences in processed spectra from different plant species while accounting for statistical differences between different plants of the same species. Specifically, the two grasses were spatially separated compared to PCA procedures in which the grasses were not clearly separated, as previously reported by Danielson et al. [9]. The three-dimensional PC-score space resulting from the MPCA analysis suggests that the greater separation of the score vectors in this three-dimensional principal component space among the six treatments is indicative of increased statistical differences among the corresponding sample spectra.

The next possible research step in evaluating the usefulness of MPCA would be an attempt to accurately different ate from among fluorometric data arising from known mixtures of plant species. If differentiation were possible and repeatable it would be logical to then investigate the usefulness of MPCA as a tool in differentiating among spectral fluorometric diet data obtained from free-ranging animals. Such information remains challenging to obtain except where highly skilled labor and money are both abundant. The utility of this approach has been suggested through preliminary results published elsewhere [17].

\section{CONCLUSIONS}

This research using MPCA as a tool to differentiate among normalized fluorometric spectral data obtained from six plant species provided positive results. As the dimensionality of the data set was increased to include solution $\mathrm{pH}$ as a third variable, it impacted the measured fluorescence signal by removing ambiguities in sample identification seen with PCA. Even without accounting for the source of variation among the individual plants within each of the six species evaluated, MPCA was able to visually separate the six species. This suggests MPCA may be a promising tool for analyzing future fluorometric data.

\section{DISCLAIMER}

Mention of a trade name does not constitute a guarantee, endorsement, or warranty of the product by the USDA-ARS or New Mexico State University over other products not mentioned.

\section{ACKNOWLEDGEMENTS}

Research funds were provided in part by the International Arid Lands Consortium (IALC, Project 03R-03) USDA Forest Service, by the USDA Cooperative State Research, Education and Extension Service and by the USDA-ARS-JER. The authors acknowledge Roy Libeau, USDA-ARS research technician, for sample preparation.

\section{REFERENCES}

[1] Stuth JW. In: Heitschmidt RK, Stuth JW, Eds. Foraging behavior in Grazing management: An ecological perspective. Portland, OR: Timber Press 1991; pp. 65-84.
[2] Mathews FP. The toxicity of the ripe fruit of blackbrush tarbush (Flourensia cernua) for sheep and goats. Texas Agric Exp Stn Bull No. 664, 1944.

[3] Dollahite JM, Allen TJ. The toxicity of the fruit of Flourensia cernua (tarbush) (blackbrush). SW Vet 1975; 28: 113-7.

[4] Gardner DR, Pfister JA. Toxic alkaloid concentrations in Delphinium nuttallianum, Delphinium andersonii, and Delphinium geyeri in the intermountain region. Rangeland Ecol Manage 2007; 60: 441-6.

[5] Díaz S, Briske DD, Mcintyre S. In: Grice AC, Hodgkinson KC, Eds. Range management and plant functional types, in Global Rangelands Progress and Prospects. New York, NY: CABI Publishing 2002; pp. 81-100.

[6] Anderson DM, Fredrickson EL, Nachman P, et al. Laser-induced fluorescence (LIF) spectra of herbaceous and woody pre- and postdigested plant material. Anim Feed Sci Tech 1998; 70: 315-37.

[7] Ourcival JM, Methy M, Burgess R. Mise enevidence, par la fluorescence de la chlorophylle, de la variabilite genotypique de la response a une contrainte hydrique chez le trefle blanc (Trifolium repens L.) et l'ivraie vivace (Lolium perenne). Can J Bot 1992; 70: 1556-62.

[8] Anderson DM, Rayson GD, Obeidat SM, et al. Use of fluorometry to differentiate among clipped species in the genera Astragalus, Oxytropis, and Pleuraphis. Rangeland Ecol Manage 2006; 59: 55763.

[9] Danielson TL, Obeidat S, Rayson GD, et al. Photoluminescent distinction among plant life forms using phosphate buffered saline extract solutions. Appl Spect 2006; 60: 800-7.

[10] Obeidat SM, Glasser T, Landau SY, et al. Application of multi-way data analysis on excitation-emission spectra for plant identification. Talanta 2007; 72: 682-90.

[11] Anderson DM, Nachman P, Estell RE, et al. The potential of laserinduced fluorescence (LIF) spectra of sheep feces to determine diet botanical composition. Small Rum Res 1996; 21: 1-10.

[12] Foley WJ, McIlwee A, Lawler I, et al. Ecological applications of near infrared reflectance spectroscopy - a tool for rapid, costeffective prediction of the composition of plant and animal tissues and aspects of animal performance. Oecologia 1998; 116: 293-305.

[13] Landau, S, Glasser T, Dvash L. Monitoring nutrition in small ruminants with the aid of near infrared reflectance spectroscopy (NIRS) technology: A review. Small Rum Res 2006; 61: 1-11.

[14] Guilbault GG, Ed. Practical Fluorescence. 2nd ed. New York, NY: Marcel Dekker, Inc 1990.

[15] Marten GC, Shenk JS, Barton FE, et al. Near infrared reflectance spectroscopy (NIRS): Analysis of forage quality. U.S. Department of Agriculture, Agriculture Handbook No. 643, 1985; p. 96.

[16] Lakowicz JR. Principles of fluorescence spectroscopy. New York, NY: Plenum Press 1983

[17] Obeidat S, Bai B, Rayson GD, et al. A multi-source portable light emitting diode spectrofluorometer. Appl Spectrosc 2008; 62: 32732 .

[18] Danielson TD, Rayson GD, Anderson DM, et al. Impact of filter paper on fluorescence measurements of buffered saline filtrates. Talanta 2003; 59: 601-4.

[19] Guo T-T, Guo L, Wang X-H, et al. Application of NIR Spectroscopy in classification of plant species. First Int. Workshop on Edu Tech Comp Sci 2009; 3: 879-83.

[20] Nørgaard L. Classification and prediction of quality and process parameters of thick juice and beet sugar by fluorescence spectroscopy and chemometry. Zuckerind 1995; 120: 970-81.

[21] Billa E, Pastou A, Monties B, et al. Multivariate chemometric analysis of the fluorescence spectra of eucalyptus wood. Ind Crops Prod 2000; 11: 187-96.

[22] Wittrup C. Comparison of chemometric methods for classification of fungal extracts based on rapid fluorescence spectroscopy. J Chemometr 2000; 14: 765-76.

[23] Nomikos P, MacGregor JF. Monitoring batch processes using multi-way principal component analysis. Am Inst Chem Eng J 1994; 40(8): 1361-75.

[24] Jolliffe IT. Principal component analysis. New York: NY, Springer-Verlag 1986; pp. 271.

[25] Wold S, Esbensen K, Geladi P. Principal components analysis. Chemometr Intel Lab Syst 1987; 2: 37-52.

[26] Jackson J.E. A User's Guide to Principal Components, New York, NY: John Wiley \& Sons 1991; p. 569. 
[27] Anderson DM, Holechek JL. Diets obtained from esophageally fistulated heifers and steers simultaneously grazing semidesert tobosa rangeland. Proc West Sec Soc Anim Sci 1983; 34: 161-4.

[28] Anderson DM, Hulet CV, Hamadeh SK, et al. Diet selection of bonded and non-bonded free-ranging sheep and cattle. Appl Anim Behav Sci 1990; 26: 231-42.

[29] Hulet CV, Anderson DM, Nakamatsu VB, et al. Diet selection of cattle and bonded small ruminants grazing arid rangeland. Sheep Res J 1992; 8(1): 11-8.

[30] Allred KW. A Field Guide to the Flora of the Jornada Plain. $2^{\text {nd }}$ ed, Range Science Herbarium. Las Cruces NM: Department of Animal and Range Sciences, New Mexico State University 1997.

[31] Yeoh S, Shi J, Langrish TAG. Comparisons between different techniques for water-based extraction of pectin from orange peels. Desalination 2008; 218(1-3, 5): 229-37.

[32] Canari R, Eyal AM. Selectivity in the extraction of lactic, malic, glutaric, and maleic acids from their binary solutions using an amine-based extractant: effect of pH. Ind Eng Chem Res 2003; 42(7): 1308-14

[33] Drake LR, Baker TR, Stark PC, et al. A laser-based spectrofluorometer for the efficient probing of metal-ion binding-sites on solid biomaterials. Inst Sci Tech 1995; 23: 57-69.

[34] Mashev LB, Popov EK, Loewen EG. Total absorption of light by a sinusoidal grating near grazing-incidence. Appl Optics 1988; 27: 152-4.

[35] Mori S, Mukai K, Yamakita J, et al. Analysis of dielectric lamellar gratings coated with anisotropic layers. J Opt Soc Am A 1990; 7(9): 1661-5.

[36] Coulombe SA, McNeil JR. Modal characteristics of short-pitch photoresist gratings exhibiting zero-order diffraction anomalies. J Opt Soc Am A 1999; 16: 2904-13.

[37] Wise BM, Gallagher NB, Butler SW, et al. A comparison of principal component analysis, multiway principal component analysis, trilinear decomposition and parallel factor analysis for fault detection in a semiconductor etch process. J Chemometr 1999; 13: 37996.

[38] Brereton RG. Chemometrics, data analysis for laboratory and chemical plant. Hoboken, NJ: John Wiley and Sons 2003; p. 489.

[39] Anderson CR, Bro R. Special issue: multiway analysis. J Chemometr 2003; 17: 200-15.

[40] Weast RC. Ed. Handbook of Chemistry and Physics. $48^{\text {th }}$ ed. Cleveland, OH: CRC Press 1967; pp. E-133.

[41] Hartley RD, Jones EC. Phenolic components and degradability of cell walls of grass and legume species. Phytochemistry 1977; 16 : $1531-4$

[42] Cook CW, Harris LE. The nutritive value of range forage as affected by vegetation type, site, and stage of maturity. Utah Agric Exp Stn Bull 344, 1950.

[43] Johnson GA, Mantha SV, Day TA. A spectrofluorometric survey of UV-induced blue-green fluorescence in foliage of 35 species. J Plant Phys 2000; 156: 242-52.

[44] Boardman NK, Thorne SW. Sensitive fluorescence method for the determination of chlorophyll a/chlorophyll b ratios. Biochim Biophys Acta 1971; 253: 222-31.

[45] Cerovic ZG, Langrand E, Latouche G, et al. Spectral characterization of $\mathrm{NAD}(\mathrm{P}) \mathrm{H}$ fluorescence in intact isolated chloroplasts and leaves: Effect of chlorophyll concentration on reabsorption of bluegreen fluorescence. Photo Res 1988; 56: 291-301.

[46] Wolfbeis OS. The Fluorescence of organic natural products, Chp 3. In: Schulman SG, Ed. Molecular luminescence spectroscopy. Methods and applications: Part I. New York, NY: John Wiley \& Sons 1985; Vol. 77: pp. 167-370.

[47] Lang M, Stober F, Lichtenthaler HK. Fluorescence emissionspectra of plant-leaves and plant constituents. Rad Environ Biophys 1991; 30: 333-4.

(C) Anderson et al.; Licensee Bentham Open.

This is an open access article licensed under the terms of the Creative Commons Attribution Non-Commercial License (http://creativecommons.org/licenses/ by-nc/3.0/) which permits unrestricted, non-commercial use, distribution and reproduction in any medium, provided the work is properly cited. 